ORIGINAL

\title{
Vegetarianism and Eating Disorder Risk Behavior in Adolescents from São Paulo, Brazil
}

\section{Camilla C.P. Estima ${ }^{a, *}$, Sonia T. Philippi ${ }^{b}$, Greisse V.S. Leal ${ }^{b}$, Carolina V.M.B. Pimentel ${ }^{b}$, and Marle S. Alvarenga ${ }^{\mathrm{b}}$}

aPRONUT - University of São Paulo, Brazil

bPublic Health School, University of São Paulo, Brazil

Received October 13, 2011; accepted June 19, 2012

\section{KEYWORDS \\ Vegetarianism; \\ Adolescents; \\ Eating disorder; \\ Diet; \\ Binge eating; \\ Compensatory \\ behaviors}

\begin{abstract}
Objective: To evaluate eating disorders risk behaviors and unhealthy weight control practices among adolescents who consider themselves as vegetarians and those who are omnivorous.

Methods: A cross-sectional study was conducted in 12 technical schools in the city of São Paulo, Brazil. The sample included 1167 adolescents (51\% female), aged 14 to 19 (mean age, 16). Adolescents stated whether they were currently vegetarian, and the sample was dichotomized as vegetarian and non-vegetarian. The two groups were compared as regards weight status, eating disorder risk behavior, unhealthy weight control methods and the perception of healthy eating.

Results: About $4 \%$ of the sample was currently vegetarian, most of them female $(70.8 \%)$, and females were 2.89 times more likely to be vegetarian than males. No relationship was found between the vegetarian status and unhealthy weight control behavior; however the vegetarian group considered their diet to be healthier than the non-vegetarian group $(\mathrm{P}=.04)$.

Conclusions: The frequency of vegetarianism, as well the frequency of eating disorder risk behaviors had no association in this adolescent sample from São Paulo, Brazil. (c) 2011 Asociación Española de Dietistas-Nutricionistas. Publicado por Elsevier España, S.L. Todos los derechos reservados.
\end{abstract}

\footnotetext{
${ }^{*}$ Corresponding author.

E-mail: camillacpestima@gmail.com (C.C.P. Estima).
} 
PALABRAS CLAVE

Vegetarianismo;

Adolescentes;

Trantornos de la

conducta alimentaria;

Dieta;

Comer en exceso:

Conductas

compensatorias
Vegetarianismo y trastornos alimentarios en adolescentes de São Paulo, Brasil

\section{Resumen}

Obj etivo: Evaluar el riesgo de trastornos alimentarios y conductas no saludables de control del peso entre adolescentes que afirman ser vegetarianos y los que afirman ser omnívoros.

Métodos: Estudio transversal realizado en 12 escuelas técnicas de la ciudad de São Paulo, Brasil. La muestra incluyó a 1.167 adolescentes (el 51\% mujeres) entre 14 y 19 años de edad (media, 16). Los adolescentes declaraban si eran vegetarianos en aquel momento, por lo que la muestra se dividió en vegetarianos y no vegetarianos. Se compararon los dos grupos en cuanto a peso, trastornos alimentarios, métodos no saludables de control del peso y la percepción de alimentación saludable.

Resultados: Cerca del 4\% de la muestra declaró ser vegetariana, la mayoría eran mujeres $(70,8 \%)$ y para las mujeres ser vegetarianas era 2,89 veces más probable que para los varones. No se encontró asociación entre ser vegetariano y los comportamientos no saludables de control del peso. Sin embargo, el grupo de vegetarianos considera que su alimentación es más saludable que la del grupo de no vegetarianos $(p=0,04)$.

Conclusiones: La frecuencia del vegetarianismo y la frecuencia de trastornos alimentarios fueron menores en esta muestra de adolescentes de São Paulo, Brasil.

(c) 2011 Asociación Española de Dietistas-Nutricionistas. Published by Elsevier España, S.L. All rights reserved.

\section{Introduction}

The vegetarian diet is the most common of the "alternative diets" and is defined as an eating pattern which does not includes meat, chicken, seafood, or products containing these foods. There are three major eating patterns of vegetarians: egg-lacto vegetarians who include egg, dairy products and milk; lacto-vegetarians who exclude eggs as well as meat, fish and chicken; and vegans who only consume vegetable foods ${ }^{1}$. The most common reasons for choosing a vegetarian diet include health considerations, concern with the environment and animal welfare, economic issues, issues about hunger around the world and religion beliefs ${ }^{2-4}$.

However, nowadays it is reported that some individuals choose a vegetarian diet due to concerns about their body weight and shape. Perry et $\mathrm{al}^{5}$ (2001) reported that the most related reason to be vegetarian in an adolescent sample was to try to lose weight or not to gain weight. On the other hand, Robinson-O'Brien et $\mathrm{al}^{6}$ (2009) observed that the concern about weight was the 5 th reason to be vegetarian among adolescents, and the first mentioned reason was the attempt to have a healthy diet.

It has been discussed that eating disorder (ED) patients commonly adopt a vegetarian diet. In this case, the vegetarianism is not related to moral issues which characterize other vegetarian individuals, but is defined as one more strategy for weight control ${ }^{2}$. Aloufy et $\mathrm{al}^{7}$ (2006) found that $85 \%$ of patients who had anorexia nervosa had admitted to be a vegetarian. The adhesion to a vegetarian diet usually occurs before, or at the same time as, the development of the ED.

Along this line, some studies have shown that vegetarians have an increased risk for ED behaviors ${ }^{6,8,9}$. Neumark-
Sztainer et $\mathrm{al}^{10}$ (1997) discussed that a vegetarian diet could be a mask for weight control concerns and practices in adolescents, and that is important to evaluate the reasons associated with the vegetarian choice. It is also important to assess the presence of ED risk behavior in individuals who adopt a vegetarian diet.

Prevalence data regarding vegetarianism in Brazil are not available, for any stage of life or on its relationship with ED. As regards ED risk behavior, studies conducted among teenagers found a frequency varying from $1.1 \%$ to $37.3 \%^{11-18}$. Considering the possible association described between vegetarian diet and ED, the aim of the present study was to evaluate ED risk behaviors and unhealthy weight control behavior methods among adolescents from São Paulo city-Brazil and who considered themselves to be vegetarians.

\section{Methods}

\section{Study Design and Sample}

This is a cross-sectional study which includes data from a larger study "Food attitudes and behaviors in adolescents from São Paulo - Brazil". It was developed to assess eating attitudes and included meal consumption, family meals, factors that determine food choice, home food availability, physical activity, and weight-related behaviors, among adolescents in Brazil, and mirrored the study design of the first wave of Project EAT ${ }^{19}$. It was conducted during 2009 in 12 technical schools in the city of São Paulo, Brazil. The sample included 1167 adolescents, 51\% female, aged 14 to 19 (mean age of 16; SD 1 year). The students provided consent forms signed by their parents to participate in the 
study. The "Food attitudes and behaviors in adolescents from São Paulo - Brazil" study was approved by the Ethics Committee of the School of Public Health at the niversity of São Paulo.

\section{Measures}

\section{Vegetarian Status}

The vegetarian status was self-reported, determined by the question: "Are you vegetarian now". a) es; b) No. Participants who answered that they were current vegetarians were asked to respond to the additional questions: "how long have you been a vegetarian" and the reasons for following a vegetarian diet.

\section{Demographics}

Participants were asked to report their birth date (to convert into age) and gender (male female).

\section{eight Status}

The height $(\mathrm{cm})$ and weight $(\mathrm{kg})$ of the students were measured by trained research staff. Body mass index (B I)for-age was calculated using percentiles developed by the orld Health Organization ( $\mathrm{HO}$ ). eight status followed the WHO cut-offs: underweight was classified at BMls-forage less than the 5th percentile; normal weight was classified for adolescents with a BMI-for-age between 5th percentile and 85th percentile; adolescents who were overweight had B Is-for-age between 85th percentile and 95th percentile; obese youths had a B I-for-age greater than the 95th percentile.

\section{Eating Disorder Ris Beha ior}

The evaluation of ED risk behavior was carried out using five questions aimed at identifying the frequency of: a) binge eating episodes; b) compensatory mechanisms, such as, purging, use of diuretics, or self-induced vomiting, with the intent of controlling weight, and c) following a very strict diet or fasting within the last 3 months.

\section{ealthy Eating Perception}

The healthy eating perception was reported by the response to the question: "Do you think that you have a healthy diet ". a) es; b) No.

\section{Data Analysis}

The sample was dichotomized as vegetarians (VE ) and non-vegetarians (NVE). All variables were analyzed according to the vegetarian status. Descriptive statistics were performed, and independent variables were tested to examine the associations between vegetarian diet and ED risk behaviors, unhealthy weight control behaviors, age, gender, and weight status. Associations between gender, age and weight status were also performed. The $\chi^{2}$ test was used to assess association with vegetarian and qualitative variables, and the student-t test for quantitative variables. Forward stepwise logistic regression was used to find possible variables of influence for being a vegetarian. All analyses were performed using the SPSS software 16.0. The significance level adopted was 0.05 . a le Characteristics of the adolescent population. São Paulo, Brazil, 2011

\begin{tabular}{lc}
\hline Variables & $\mathrm{n}(\%)$ \\
\hline Gender & \\
$\quad$ ale & $595(51.0)$ \\
Female & $572(49.0)$ \\
Weight status & \\
$\quad$ nderweight & $12(1.0)$ \\
Normal weight & $830(72.3)$ \\
Overweight & $194(16.9)$ \\
Obese & $112(9.8)$ \\
Current vegetarian & \\
$\quad$ es & $48(4.1)$ \\
Reasons for being a vegetarian & \\
$\quad$ eight control & $1(5.0)$ \\
ant to have healthier diet & $1(5.0)$ \\
Environment care & $5(25.0)$ \\
Do not want to kill the animals & $7(35.0)$ \\
Taste of the meat & $4(20.0)$ \\
Other reasons & $2(10.0)$ \\
Eating disorder risk behavior & \\
Binge eating, yes & $120(10.3)$ \\
$\quad$ se of laxatives, yes & $4(0.3)$ \\
$\quad$ se of diuretics, yes & $16(1.4)$ \\
Self-induced vomiting, yes & $4(0.3)$ \\
Strict dieting fast, yes & $100(8.6)$ \\
Consider to have a healthy eating, yes & $492(42.3)$ \\
\hline
\end{tabular}

\section{Results}

The profile of sample is shown in Table 1. Of the 1167 adolescents evaluated, $51 \%$ were male and $49 \%$ were female. The majority of them had a normal weight status (72.3\%). A total of 48 students reported that they were currently VE (4.1\%), and the reasons for following a vegetarian diet were, in decreasing order: a) did not want to kill the animals; b) environment care; c) taste of the meat; d) other reasons, and e) weight control, and wanting to have a healthier diet.

As regards ED risk behavior, $10.3 \%$ reported binge eating episodes. The practice of strict dieting or fasting, at least once a week, was reported by $8.6 \%$ of the adolescents. The use of diuretics, laxatives and self-induced vomit were infrequent (Table 1). No relationship was found between being vegetarian and any ED risk behavior (Table 2). Furthermore, $52.3 \%$ of the adolescents had unhealthy weight-control behaviors, but no relationship was found between these and being VE (Tables 1 and 2).

hen asked if the adolescents considered having a healthy diet, $57.7 \%$ of the sample answered "no" (Table 1). An association was observed between considering themselves to have a healthy diet and being VE $\quad(P=.04)$ (Table 2).

A relationship was found between gender and stating to have a healthy diet and being VE . ore females than males followed a vegetarian diet, and more adolescents who considered they had a healthy diet were VE (Table 2). 
a le Relationships between vegetarian status and gender, weight status, eating behaviors and healthy eating among youths. São Paulo, Brazil, 2011

\begin{tabular}{lccl}
\hline & $\begin{array}{l}\text { Non- } \\
\text { vegetarians, } \\
\mathrm{n}(\%)\end{array}$ & $\begin{array}{l}\text { Vegetarian, } \\
\mathrm{n}(\%)\end{array}$ & $\mathrm{P}$ \\
\hline $\begin{array}{l}\text { Gender } \\
\quad \text { ale }\end{array}$ & $575(51.8)$ & $14(29.2)$ & .002 \\
$\quad \begin{array}{l}\text { Female } \\
\text { Weight status }\end{array}$ & $535(48.2)$ & $34(70.8)$ & \\
$\quad$ & & & \\
$\quad$ nderweight & $11(1.0)$ & 0 & .287 \\
$\quad$ Normal weight & $774(72.2)$ & $39(84.8)$ & \\
$\quad$ Overweight & $183(17.1)$ & $5(10.9)$ & \\
$\quad$ Obese & $104(9.7)$ & $2(4.3)$ & \\
Binge eating & $112(10.1)$ & $7(14.6)$ & .328 \\
$\quad$ se of laxatives & $4(0.4)$ & 0 & .999 \\
$\quad$ se of diuretics & $15(1.4)$ & $1(2.1)$ & .495 \\
Self-induced vomiting & $3(0.3)$ & $1(2.1)$ & .156 \\
Strict dieting fast & $97(8.8)$ & $2(4.2)$ & .426 \\
Consider to have a & $460(41.6)$ & $27(56.3)$ & .044 \\
healthy eating & & & \\
\hline
\end{tabular}

It was found that females were more 2.89 times more likely to be VE than males, when the possible variables that influenced being VEG were assessed (data not shown).

\section{Discussion}

This is the first study conducted in Brazil that evaluated the relationship between vegetarianism and ED risk behavior in a large sample of adolescents from public schools in São Paulo, Brazil. Out of the total, 4.1\% $(n=48)$ considered themselves to be vegetarian, and of those $70.8 \%$ were female, with significant difference between gender. The prevalence of vegetarianism in other studies among adolescents ranged between $2.5 \%$ and $6 \%$ and, like the present study the majority of the vegetarian adolescents were female; on average, the prevalence of female VE was over $70 \% 5,6,8,9,20,21$. One reason for finding more female adolescents who follow a vegetarian diet may be that they are more concerned about their body weight and shape $e^{5,22}$.

In the present study, the main reasons given for following a vegetarian diet were: did not want to kill the animals, environmental care, and the taste of the meat. Similar to these findings, Greene-Finestone et $\mathrm{al}^{20}(2008)$ found that that the main reason was animal rights in 630 Canadian adolescents. Some studies found the weight control issue to be one of the least common reasons for being a vegetarian $6,8,22$. However, Perry et $\mathrm{al}^{5}$ (2001) reported that trying to lose weight was the most important reason to have a vegetarian diet. On the other hand, Robinson-O'Brien et $\mathrm{al}^{6}$ (2009) found that "to be healthy" was the first reason for vegetarian choice. In the present study, this was in 5th place, along with "weight worries".

The differences among the reasons found for being a vegetarian may be due to the fact that being vegetarian in estern countries is not common or cultural. In Brazil, for example, the usual diet is based on foods rich in refined carbohydrate (such as rice), beans and meat, and is also poor in fruits and vegetables ${ }^{23}$. Brazil has one of the largest cattle herds in the world, and is one of the top exporters of beef. oreover, meat consumption in Brazil is on the increase.

nlike Robinson-O'Brien et $\mathrm{al}^{6}$ (2009), Perry et $\mathrm{al}^{5}$ (2001), and reene-Finestone et $\mathrm{al}^{20}(2008)$, the present study did not find any relationship between being a vegetarian and ED risk behavior. Although the relationship was not significant, the use of diuretics and vomiting were higher among the vegetarian group, and the use of laxatives and fasting were higher in the NVE group. It must be stressed that the frequency of any ED risk behavior in this sample was lower compared with that of other studies. ust one study used the same questions to evaluate ED risk behavior among teenagers in Brazil $^{17}$ and it found that $37.3 \%$ practiced binge eating, $24.7 \%$ dieted, and the other questions were reported by less than $3 \%$ of participants. Other Brazilian studies mostly used the Eating Attitude Test to assess ED risk behavior, which can overestimate the risk. No significant difference in weight status was found between the VE and NVE . However, the frequency of overweight and obesity was lower in the vegetarian sample $(15.2 \% \mathrm{VE}$, and $26.8 \%$ NVE ). The same pattern was observed in other studies with a higher prevalence of overweight in NVE than in vegetarians $(5,6,8)$, except for the study by reeneFinestone et $\mathrm{al}^{20}$ (2008), which found that $20 \%$ of the vegetarian group was overweight compared to $17 \%$ of the non-vegetarians.

According to American Dietetic Association position ${ }^{24}$, when well planned, the vegetarian diet is healthier, more nutrient dense, can prevent, and also be part of the treatment of, many diseases, more than a non-vegetarian diet. Furthermore, children and adolescents who engage into a vegetarian diet have an adequate growth and development ${ }^{25}$, and consume more soy ${ }^{26}$. The higher consumption of more healthy foods like fruits, vegetables and milk, may lead to the vegetarian diet being protective against becoming overweight and obesity.

The vegetarian adolescents were more likely to consider their diet as healthy. This result supports previous findings that showed VE are more concerned about having a healthier diet ${ }^{5,27}$. The vegetarian diet is a style of eating that can lead to a healthier life and eating habits ${ }^{25}$, such as decreased consumption of fat, cholesterol, and a higher intake of fiber, vitamin, minerals ${ }^{21,24,28}$, and they meet the food consumption recommendations ${ }^{5}$. This pattern may play a role in obesity prevention through a mechanism associated with reduced energy density and increased satiety.

Although finding that a well planned and healthy vegetarian diet could be appropriate for all stages of life, the risk of finding more eating behaviors disorders in vegetarian adolescents should be considered ${ }^{6}$. Furthermore, the definition about what is truly a healthy diet must be discussed with this group. There are currently some very restricted (and sometimes dysfunctional) ideas about what is "healthy eating" ${ }^{29}$ and it is important to stress, that in order to be healthy, there should be no major restriction in the diet 29,30 . 
The present study has some limitations. First concerning the study design, since it is a cross-sectional it is not possible to demonstrate cause-effect between vegetarianism and ED risk behaviors. Secondly, the number of vegetarians among the group was small (48 out of 1167 students), and the lack of a relationship between being vegetarian and unhealthy weight control behaviors could be due the sample size. There are no available data about the vegetarian population in Brazil, particularly in adolescents, and more studies are needed in this field.

Although there are many instruments developed to specifically evaluate eating disorder behaviors, the questionnaire used for this project was developed based on a questionnaire used in a well-established study about adolescent attitudes ${ }^{19}$. The instrument includes several questions regarding unhealthy weight control behaviors developed by Hay et $\mathrm{al}^{31}$ (1998) that were adapted to Brazilian adolescents ${ }^{32}$. Despite the fact it was not validated to assess the aims of the study, it generated valid data on ED risk behavior and vegetarianism practice among teenagers ${ }^{6}$; and it is believed that it could replicated and used in different populations, such as in the present study.

The use of questionnaires and scales to evaluate ED behaviors is always a common limitation; nonetheless it would probably be the same with any instrument used with this objective due to the severity and stigma surrounding ED.

Finally, as regards the vegetarian status, a self-reported measure was used to identify the adolescents who considered themselves to be vegetarians, and it was assessed through a single survey item question. However, a well conducted survey on this theme among adolescents gave the same results ${ }^{19}$. Even more, the food consumption of the vegetarian and non-vegetarian groups was not analyzed to confirm if the vegetarians had a healthier food intake as they reported, and further studies are needed to check this information.

Despite the low number of vegetarians in the present sample, it is in accordance with the previous studies where we found a small number of adolescents who reported to be VE . ore studies with vegetarians in Brazil are needed to understand this choice of diet. The aim of the present study was to evaluate ED risk behaviors and unhealthy weight control behavior methods among adolescents who considered themselves to be vegetarians and did not find any significant relationship between being a vegetarian and ED risk behavior. However, even if this relationship was not significant, the vegetarian group reported more binge eating and use of diuretics. These results indicate that vegetarian population practices need to be specifically evaluated in order to prevent the development of eating disorders.

\section{inancing}

The authors would like to thank The State of Sao Paulo Research Foundation (FAPESP) (process number 2009 72246) for the grant that supported this research.

\section{Conflict of Interests}

The authors declare no conflicts of interests.

\section{Re erences}

1. American Dietetic Association (ADA). Position of the American Dietetic Association of Canada: vegetarian diets. Am Diet Assoc. 2009;109:1266-82.

2. aspar S. Vegetarianismo adolescente como uma expressão da anorexia nervosa: apresenta ão de uma proposta analítica. Anal Psicol. 1999;2:307-16.

3. Lea E, orsley A. The cognitive contexts of beliefs about the healthiness of meat. Public Health Nutr. 2002;5:37-45.

4. arlow H , Hayes , Soret S, Carter RL, Schwab ER, Sabaté . Diet and the environment: does what you eat matter Am Clin Nutr. 2009;89:S1699-703.

5. Perry CL, c uire T, Neumark-Sztainer D, Story . Characteristics of vegetarian adolescents in a multiethnic urban population. Adol Health. 2001;29:406-16.

6. Robinson-O'Brien R, Perry CL, all , Story , Neumark-Sztainer $\mathrm{D}$. Adolescent and young adult vegetarianism: better dietary intake and weight outcomes but increased risk of disordered eating behaviors. Am Diet Assoc. 2009;109:648-55.

7. Aloufy A, Latzer . Diet or health - the linkage between vegetarianism and anorexia nervosa. Harefuah. 2006;145:526-31.

8. Bas , arabudak E, iziltan . Vegetarianism and eating disorders: association between eating attitudes and other psychological factors among Turkish adolescents. Appetite. 2005;44:30915.

9. lopp SA, Heiss C, Smith HS. Self-report vegetarianism may be a marker for college women at risk for disordered eating. Am Diet Assoc. 2003;103:745-7.

10. Neumark-Sztainer D, Story , Resnick D, Blum R . Adolescent vegetarians: A behavioral profile of a school-based population in innesota. Arch Pediatr Adolesc ed. 1997;151:833-8.

11. Dunker LL, Philippi ST. Hábitos e comportamentos alimentares de adolescentes com sintomas de anorexia nervosa. Rev Nutr. 2003;16:51-60.

12. Nunes A, Barros FC, Olinto A T, Camey S, ari D. Prevalence of abnormal eating behaviours and inappropriate methods of weight control in young women from Brazil: a populationbased study. Eat eight Disord. 2003;8:100-6.

13. Vilela $E$, Lamounier A, Filho AD, Neto RB, Horta . Eating disorders in school children. Pediatr. 2004;80:49-54.

14. oya T, Fleitlich-Bilyka B, oodman R. Brief report: oung people at risk for eating disorders in Southeast Brazil. Adolesc. 2006;29:313-7.

15. Souza- aneshima A, Fran a AA, neube DPF, aneshima EN. Ocorr ncia de anorexia nervosa e dist rbio de imagem corporal em estudantes do ensino médio de uma escola da rede $\mathrm{p}$ blica da cidade de aringá, Estado do Paraná. Acta Sci Health Sci. 2006;28:119-27.

16. Alves E, Vasconcelos FA, Calvo C, Neves . Preval ncia de sintomas de anorexia nervosa e insatisfa ão com a imagem corporal em adolescentes do sexo feminino do unicípio de Florianópolis, Santa Catarina, Brasil. Cad Sa de P blica. 2008;24:50312.

17. Ferreira ES, Veiga V. Eating disorder risk behavior in Brazilian adolescents from low socio-economic level. Appetite. 2008;51:249-55.

18. Vale A O, err LRS, Bosi L . Risk behaviors for eating disorders among female adolescents from different social strata in the Brazilian Northeastern. Ci nc Sa de Colet. 2011;16:12132.

19. Neumark-Sztainer D, Story , Hannan P, Croll . Overweight status and eating patterns among adolescents: where do youths stand in comparison with the healthy people 2010 objectives Am Public Health. 2002;92:844-51.

20. reene-Finestone LS, Campbell , Evers SE, utmanis IA. Attitudes and health behaviors of young adolescent omnivores 
and vegetarians: a school based study. Appetite. 2008;51:10410.

21. Farmer B, Larson BT, Fulgoni VL, Rainville A, Liepa . A vegetarian dietary pattern as a nutrient-dense approach to weight management: an analysis of National Health and Nutrition Examination Survey 1999-2004. Am Diet Assoc. 2011;111:819-27.

22. Fisak BF, Peterson RD, Tantleff-Dunn S, olnar . Challenging previous conceptions of vegetarianism and eating disorders. Eat eight Disord. 2006;11:195-200.

23. Pesquisa de or amentos familiares 2008-2009. Antropometria e estado nutricional de crian as, adolescentes e adultos no Brasil. Rio de aneiro: IB E; 2010.

24. American Dietetic Association (ADA). Position of the American Dietetic Association: vegetarian diets. Am Diet Assoc. 1997;97:1317-21.

25. Dunham L, ollar L . Vegetarian eating for children and adolescents. Pediatric Health Care. 2006;20:27-34.

26. Freitas ECB, Alvarenga S, Scaglisui FB. Avalia ão do conhecimento nutricional e freq ncia de ingestão de grupos alimen- tares em vegetarianos e não vegetarianos. Rev Bras Nutr Clin. 2006;21:267-72.

27. Bedford L, Barr SI. Diets and selected lifestyle practices of self-defined adult vegetarians from a population-based sample suggest they are more health conscious'. Int Behav Nutr Phys Act. 2005;2:4.

28. American Dietetic Association (ADA). Position of the American Dietetic Association of Canada: vegetarian diets. Am Diet Assoc. 2003;103:748-65.

29. artins CT, Alvarenga S, Vargas SVA, Sato SC, Scagliusi FB. Ortorexia nervosa: reflexões sobre um novo conceito. Rev Nutr. 2011;24:345-57.

30. American Dietetic Association (ADA). Total diet approach to communicating food and nutrition information. Am Diet Assoc. 2007;107:1224-32.

31. Hay PH. The epidemiology of eating disorder behaviors: An Australian community-based survey. Eat Disord. 1998;23:371-82.

32. Ferreira ES, Veiga V. Eating disorder risk behavior in Brazilian adolescents from low socio-economic level. Appetite. 2008;51:249-55. 